\title{
Facts of Rheumatoid Arthritis (RA)
}

\section{Chaitany Patel ${ }^{1 *}$, Vaibhavi Parmar ${ }^{1}$ and Dipal Patel ${ }^{\mathbf{2}}$}

${ }^{1}$ Assistant Professor, Neurological and Sports Department, Shree B.G. Patel College of

Physiotherapy, Sardar Patel University, India

${ }^{2}$ Clinical Therapist, Neurological and Sports Department, Shree B.G. Patel College of

Physiotherapy, Sardar Patel University, India

*Corresponding Author: Chaitany Patel, Assistant Professor, Neurological and Sports

Department, Shree B.G. Patel College of Physiotherapy, Sardar Patel University, India.
Received: August 24, 2020

Published: September 01, 2020

(C) All rights are reserved by Chaitany

Patel., et al.
The most common type of autoimmune arthritis is called Rheumatoid arthritis. Mainly caused by when the immune system is not working properly. Rheumatoid arthritis symptom pain and swelling in the wrist and small joints of the hand and feet.

According one research, worldwide the incidence of RA ranges is $0.3-1.5 \%$ and in India is $0.28-0.7 \%$ and in European countries 40 per $1,00,000$. Most common cases seen in women about $75 \%$ and fact is 1 - 3\% of women get rheumatoid arthritis in their lifetime. RA disease most of seen in ages of 30 and 50 .

Rheumatoid arthritis is a chronic disease leads to stiffness, swelling, joint pain and decreased movement of the joints. hands and feet are most commonly affected. RA can affect your organs, such as eyes, skin or lungs according their duration and severity.

Rheumatoid arthritis mainly diagnosed by blood test examination and X-ray as arthritis changes but seen in smaller joint and symptoms will need to be present for more than three months to consider this diagnosis.

Medical management and rehabilitation for RA leads to stop joint pain, swelling and prevents joint damage. Early medical management as well as physiotherapy give better long term results.

In RA cases, physiotherapy modified exercises like Regular low-impact exercises, such as walking, and exercises can increase muscle strength. This will improve your overall health and lower pressure on your joints and its more benefited.

Hand exercise most effective in early as well as late rehabilitation in RA cases and treatment duration about 1.5 hour do like- joint protection, controlled symptom and do functional activity maximum with correction of movement

Muscles Strengthening and Stretching exercises in RA Hand (SARAH) is a progressive exercise program for people having difficulties with wrist and hand function.

Resent research about cost effective rehabilitation mainly iSAR$\mathrm{AH}$ is the first Web-based learning resource which help therapist and patients with evidence-based hand exercise program which is systematic design approach and to improve hand function, was safe to deliver.

Research show, people who receive early treatment for RA feel better, well controlled symptom, diseases may progress but in slow rate and are more likely to lead an active life.

\section{Assets from publication with us}

- Prompt Acknowledgement after receiving the article

- Thorough Double blinded peer review

- Rapid Publication

- Issue of Publication Certificate

- High visibility of your Published work

Website: https://www.actascientific.com/

Submit Article: https://www.actascientific.com/submission.php

Email us: editor@actascientific.com

Contact us: +919182824667 